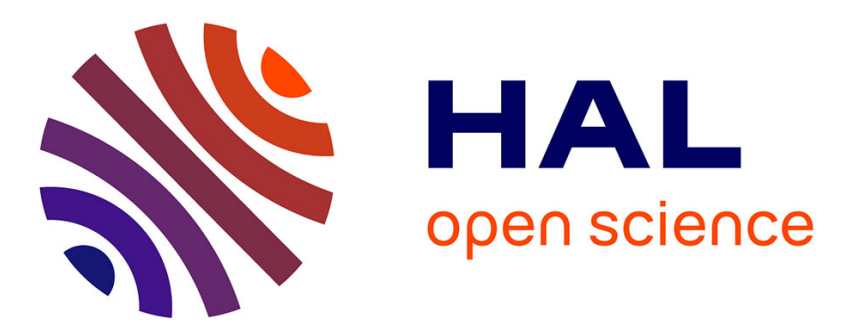

\title{
A quick journey into the diversity of iron uptake strategies in photosynthetic organisms
}

Amanda Martín-Barranco, Sébastien Thomine, Grégory Vert, Enric Zelazny

\section{To cite this version:}

Amanda Martín-Barranco, Sébastien Thomine, Grégory Vert, Enric Zelazny. A quick journey into the diversity of iron uptake strategies in photosynthetic organisms. Plant Signaling and Behavior, 2021, 10.1080/15592324.2021.1975088 . hal-03358737

\section{HAL Id: hal-03358737 https://hal.inrae.fr/hal-03358737}

Submitted on 8 Nov 2021

HAL is a multi-disciplinary open access archive for the deposit and dissemination of scientific research documents, whether they are published or not. The documents may come from teaching and research institutions in France or abroad, or from public or private research centers.
L'archive ouverte pluridisciplinaire HAL, est destinée au dépôt et à la diffusion de documents scientifiques de niveau recherche, publiés ou non, émanant des établissements d'enseignement et de recherche français ou étrangers, des laboratoires publics ou privés. 
1 A quick journey into the diversity of iron uptake strategies in photosynthetic organisms

3

4 Amanda Martín-Barranco ${ }^{1}$, Sébastien Thomine ${ }^{1}$, Grégory Vert ${ }^{2}$ and Enric Zelazny ${ }^{3 *}$

5

$6{ }^{1}$ Institute for Integrative Biology of the Cell (I2BC), UMR9198 CNRS/CEA/Univ. Paris Sud, Université 7 Paris-Saclay, 91198 Gif-sur-Yvette, France.

8 2Plant Science Research Laboratory (LRSV), UMR5546 CNRS/University of Toulouse 3, 31320 Auzeville 9 Tolosane, France.

$10{ }^{3}$ BPMP, CNRS, INRAE, Montpellier SupAgro, Université Montpellier, 2 Place Viala, 34060 Montpellier 11 Cedex 2, France.

*Correspondence to: enric.zelazny@cnrs.fr 


\section{Abstract}

Iron $(\mathrm{Fe})$ is involved in multiple processes that contribute to the maintenance of the cellular homeostasis of all living beings. In photosynthetic organisms, Fe is notably required for photosynthesis. Although iron is generally abundant in the environment, it is frequently poorly bioavailable. This review focuses on the molecular strategies that photosynthetic organisms have evolved to optimize iron acquisition, using Arabidopsis thaliana, rice (Oryza sativa), and some unicellular algae as models. Nongraminaceous plants, including Arabidopsis, take up iron from the soil by an acidification-reductiontransport process (strategy I) requiring specific proteins that were recently shown to associate in a dedicated complex. On the other hand, graminaceous plants, such as rice, use the so-called strategy II to acquire iron, which relies on the uptake of $\mathrm{Fe}^{3+}$ chelated by phytosiderophores that are secreted by the plant into the rhizosphere. However, apart these main strategies, accessory mechanisms contribute to robust iron uptake in both Arabidopsis and rice. Unicellular algae combine reductive and non-reductive mechanisms for iron uptake and present important specificities compared to land plants. Since the majority of the molecular actors required for iron acquisition in algae are not conserved in land plants, questions arise about the evolution of the Fe uptake processes upon land colonization.

Keywords: iron uptake strategies, photosynthetic organisms, iron-acquisition complex.

(1)

0 \\ 1}

2

53

\section{4}




\section{Introduction}

Iron (Fe) is essential for every form of life. Photosynthetic organisms especially need this element for the electron transport chain in photosynthetic systems, which in land plants are located in the thylakoid membranes of chloroplasts. Each photosystem I unit requires 4 FeS cluster cofactors, i.e. 12 Fe atoms, for functioning. ${ }^{1}$ Plants concentrate up to $80 \%$ of cellular Fe in chloroplasts, making these organelles the major Fe sinks. ${ }^{2}$ In addition, Fe is needed for many key functions common to most organisms such as electron transport in the respiratory chain and Fe is a cofactor in enzymes involved in reactive oxygen detoxification and DNA replication, among others. ${ }^{3-5}$ On the other hand, the redox properties of Fe make it potentially toxic. Fe reacts with hydrogen peroxide in the Fenton reaction to generate highly toxic hydroxyl radicals. For this reason, cellular Fe accumulation must be under tight control and iron has to be sequestered either in storage proteins, such as ferritins, or in organelles such as the vacuole. ${ }^{6,7}$ Iron acquisition represents a major challenge for land plants and algae, due to the exceedingly low solubility of Fe. ${ }^{8}$ In this minireview, we present the different mechanisms of iron uptake in photosynthetic organisms that play a crucial role in the maintenance of iron homeostasis.

\section{Main iron-acquisition strategies of land plants: Arabidopsis thaliana and Oryza Sativa as model organisms.}

Although iron is generally abundant in aerobic soils, it tends to form oxyhydrates of ferric iron $\left(\mathrm{Fe}^{3+}\right)$ of low solubility at neutral or alkaline $\mathrm{pH} .{ }^{9}$ Plants evolved two major strategies to increase the solubility of immobile iron pools. All land plant species except the grasses use a three-step process, called strategy I, based on the acidification-reduction-transport triad, ${ }^{10}$ that has been well described in the model plant Arabidopsis thaliana (Fig. 1A). Briefly, soil acidification facilitates the dissolution of $\mathrm{Fe}^{3+}$ precipitates and increases iron availability by several orders of magnitude. The subsequent reduction of ferric chelates weakens the stability of the chelates and releases ferrous iron $\left(\mathrm{Fe}^{2+}\right)$. $\mathrm{Fe}^{2+}$ is finally taken up by an iron transporter into root cells. ${ }^{7,11}$ This strategy is strongly inhibited in soils with high $\mathrm{pH}$ or with high bicarbonate levels. In calcareous soils, which represent $30 \%$ of arable land, the protons released by iron-deficient plants are buffered by bicarbonates ${ }^{11,12}$ and ferric chelate reduction is strongly impaired. ${ }^{13-15}$ Graminaceous plants, such as Oryza sativa, use the so-called strategy II to take up iron (Fig. 1B), relying on the release in the soil of mugineic acid-type, hexadentate chelators, called phytosiderophores. ${ }^{16,17}$ These organic compounds bind $\mathrm{Fe}^{3+}$ and are taken up as intact $\mathrm{Fe}^{3+}-$ phytosiderophore complexes without the requirement of a reduction step. ${ }^{18}$ In contrast to reductionbased Fe acquisition developed by strategy I plants, phytosiderophore-dependent Fe chelation and uptake are largely insensitive to high soil $\mathrm{pH}^{10}$ 


\section{The core of the iron uptake machinery}

Extensive study of the model strategy I plant Arabidopsis thaliana revealed the identity of the genes encoding the core components of the acidification-reduction based strategy (Fig. 1A). Rhizosphere acidification is mediated by proton extrusion by the AHA family of P-type $\mathrm{H}^{+}$-ATPase. In roots, the Arabidopsis plasma membrane $\mathrm{H}^{+}$-ATPase 2 (AHA2) is the major ATPase isoform ${ }^{19}$ and has been shown to be expressed in epidermal cells including root hairs, in the cortex, and in phloem and xylem parenchyma cells. ${ }^{20,21}$ Although AHA2 clearly participates in many biological functions in plants, the fact that AHA2 transcripts accumulate to higher levels under iron-deficient conditions clearly argues for its contribution to the acidification-driven iron uptake process. Accordingly, loss of AHA2 function impairs proton extrusion capacity upon iron shortage. The reduction of soluble ferric iron is carried out by the Ferric Reduction Oxidase 2 (FRO2). The ferric reductase defective-1 or frd1 mutant, defective in the $F R O 2$ gene, is impaired in iron deficiency-induced ferric chelate and copper reductase activity, accumulates less iron and is severely chlorotic. ${ }^{22}$ Since $F R O 2$ expression is regulated by iron but not copper, ${ }^{23,24}$ the major function of FRO2 appears to be associated with iron uptake. FRO2 transfers electrons from NADPH in the cytoplasmic side via flavin and two heme groups to apoplastic $\mathrm{Fe}^{3+}$, thus producing $\mathrm{Fe}^{2+} .{ }^{25}$ Reduced iron is then taken up by the root epidermis-expressed metal transporter Iron Regulated Transporter 1 (IRT1). IRT1 is poorly selective and mediates the uptake of other divalent non-iron metals such as zinc, manganese, cobalt or cadmium. ${ }^{26-30}$ The fact that among all these metals only iron regulates IRT1 transcription points to the specific involvement of IRT1 to iron uptake, ${ }^{30}$ with other metals being non-specifically transported during this process. As a consequence, an irt1 knockout mutant is strongly chlorotic due to low iron accumulation in plant tissues and is defective for the low iron-induced accumulation of zinc, manganese or cobalt. ${ }^{30}$ Interestingly, the expression of the genes encoding the core of the iron uptake machinery, i.e. IRT1, FRO2 and AHA2, is activated under iron-limited conditions by the same basic Helix-Loop-Helix (bHLH) transcription factor called FER-like Iron Deficiency-Induced Transcription Factor (FIT) that can form heterodimers with other bHLH proteins. $^{31-33}$

\section{Coumarins contribute to robust iron uptake in Arabidopsis}

As mentioned above, the acidification and FRO-dependent reduction perform rather poorly in alkaline soils, and are assisted by a second shell of mechanisms that contribute to robust iron uptake. The secretion of phenolic compounds, organic acids, flavonoids, and flavins has also been involved in the acidification-reduction strategy to take up iron. ${ }^{34-39}$ In particular, a class of coumarin-type siderophores derived from the phenylpropanoid pathway assists the membrane-bound acidification and ferric 
reduction by solubilizing and reducing iron from insoluble sources (Fig. 1A). pH modulates the biosynthesis of coumarins, with the main catechol coumarin fraxetin being produced at alkaline $\mathrm{pH}$ while acidic $\mathrm{pH}$ favors sideretin. ${ }^{40}$ Coumarin biosynthesis requires the Feruloyl coenzyme A $6^{\prime}$ hydrozylase 1 ( $\left(6^{\prime} \mathrm{H} 1\right)$ enzyme, whose gene is induced upon low iron condition. ${ }^{38}$ Mutants defective in $\mathrm{F}^{\prime} \mathrm{H} 1$ are chlorotic and more sensitive to iron deficiency, ${ }^{38}$ highlighting the role of coumarins in iron uptake. Coumarins are secreted in the rhizosphere through the ABC-type transporter ABCG37/PDR9 (Fig. 1A), and ABCG37/PDR9 expression is also boosted by iron shortage. ${ }^{41}$ Besides their direct role in increasing iron availability, coumarins also modify the root microbiota-mediated iron solubilization to further exploit low iron sources in the soil. The latter role of coumarins again depends on the plant iron uptake machinery. ${ }^{42}$ In addition to IRT1, other metal transporters likely contribute to iron acquisition from the soil. The Natural Resistance-Associated Macrophage Protein 1 (NRAMP1) metal transporter is upregulated under Fe deficiency and behaves as a low affinity iron transporter, backing up IRT1 when iron concentrations are suboptimal. ${ }^{43,44}$

\section{Spatial regulation of iron uptake at the plasma membrane}

Besides the preferred transcription of $F R O 2$ and IRT1 genes in root epidermal cells under iron-limited conditions, several post-translational events target the core of the iron uptake machinery. The first mechanism involves the degradation of IRT1 when plants face an excess of zinc, manganese or cobalt. Contrary to iron, these metals do not require prior reduction by FRO2 to be transported by IRT1. Upon high influx of zinc, manganese or cobalt through IRT1, these non-iron metals are sensed by a histidinerich motif in a large cytosolic loop of IRT1 that is likely sitting at the exit of the metal permeation domain. ${ }^{45}$ Non-iron metal binding to this histidine-rich motif allows the recruitment of the Calcineurin B-like (CBL)-interacting serine/threonine-protein kinase 23 (CIPK23) and phosphorylation of neighboring serines and threonines. These act as a docking site for the E3 ubiquitin ligase IRT1 DEGRADATION FACTOR1 (IDF1) that mediates the K63 polyubiquitination of IRT1 and its endocytic trafficking to the vacuole for degradation. ${ }^{45}$ This non-iron metal-dependent degradation of IRT1 takes place in soil patches rich in zinc, manganese or cobalt and limits the acquisition of these potentially toxic elements, while IRT1 safely takes up iron where non-iron metals are low. Besides CIPK23 and IDF1, the peripheral membrane protein ENHANCED BENDING1 (EHB1) was demonstrated to interact with and negatively regulate IRT1 in a calcium-dependent manner, leading to a reduction of iron acquisition in plant. ${ }^{46}$ One hypothesis proposed by Khan and co-workers is that EHB1 might be implicated in IRT1 endocytosis, as suggested by an increase in IRT1 protein content in ehb1 mutants and the fact that proteins from the same family can induce membrane tubulation in vitro. 
In addition to the regulated trafficking of IRT1, recent data suggest that the formation of a protein complex involving AHA2-FRO2-IRT1 may also be important to optimize Fe uptake at the plasma membrane (Fig. 1A). ${ }^{47}$ All three proteins were demonstrated to co-localize at the cell surface. AHA2 shows an even distribution while both FRO2 and IRT1 display a polar localization, being enriched at the outer plasma membrane domain facing the rhizosphere. ${ }^{45,47,48}$ The close proximity of FRO2 and IRT1 may allow the funneling of iron by coupling reduction and transport. This complex likely facilitates iron uptake in the aerobic soil environment, by limiting the re-oxidation of FRO2-produced ferrous iron. The association of AHA2 may create a local acidic $\mathrm{pH}$ environment in the vicinity of FRO2 to avoid the detrimental effects of high $\mathrm{pH}$ or bicarbonates on ferric reduction. The functional relevance of such protein complex is still unclear and will await the identification of factors or residues in AHA2-FRO2IRT1 important for its formation. Whether AHA2, FRO2 and IRT1 form an obligate protein complex for efficient iron transport remains to be determined. Interestingly, overexpression of IRT1 or FRO2 alone can increase Fe uptake. ${ }^{23,49}$ The fact that both FRO2 and IRT1 are limiting for iron acquisition argues against a scenario in which a stoichiometric complex between AHA2, FRO2 and IRT1 is required for efficient Fe uptake. This suggests that a pool of free FRO2 or IRT1 localized at the plasma membrane may contribute to iron import into root epidermal cells. Until now, FRO2 and IRT1 were reported to strictly co-localize at the outer plasma membrane domain of root epidermal cells. ${ }^{47}$ The limit of resolution of confocal microscopes however prevents us from reaching definitive conclusions. The development of super-resolution imaging approaches with FRO2 and IRT1 will certainly help visualize free and complex-loaded FRO2 and IRT1 proteins at the cell surface. Regardless, the stability of the AHA2-FRO2-IRT1 complex is regulated by non-iron metal transport. Indeed, elevated levels of zinc, manganese or cobalt trigger IRT1 internalization and vacuolar degradation, while AHA2 and FRO2 seem to be largely unaffected. ${ }^{47}$ The disassembly of the complex is driven by CIPK23-mediated phosphorylation of IRT1 upon non-iron metal excess. The fate of the released AHA2 and FRO2 has not been determined but they likely engage in other processes at the cell surface. AHA2 being central to proton extrusion most likely participates to many other cellular processes while FRO2 may contribute to copper reduction.

The existence of the AHA2-FRO2-IRT1 complex raises the possibility that additional proteins involved in iron uptake may also be found in a higher order protein complex. The Feruloyl-Coenzyme A 6'Hydroxylase 1 (F6'H1) coumarin biosynthetic enzyme and the ABC-type transporter ABCG36/PDR8, a close homolog of the PDR9 coumarin efflux transporter, were identified in IRT1 interactome. ${ }^{47}$ Both PDR9 and PDR8 are found in the outer plasma membrane domain of root epidermal cells, ${ }^{50}$ thus coexisting in the same polar domain as FRO2 and IRT1. Although PDR9 was demonstrated to secrete coumarins for iron nutrition, PDR8 was reported to export various molecules including antimicrobial 
metabolites, cadmium or indole 3-butyric acid. ${ }^{51-55}$ However, considering that $A B C$ transporters usually show overlapping substrate specificity, even for root exudation, ${ }^{56}$ the possibility that PDR8 is also involved in exudation of iron uptake-related coumarins should be considered. Metabolite profiling of pdr8 and pdr9 mutants however suggest that PDR9 but not PDR8 transport phenolic compounds, including coumarin. ${ }^{57}$ Considering that the low affinity iron transporter NRAMP1 also uses ferrous iron as substrate, it may also associate with FRO2 for efficient iron transport. The exciting possibility that a higher order protein complex gathering the major actors of the primary iron uptake machinery and the accessory proteins in an acidification-reduction-transport platform dedicated to iron uptake will deserve more attention in the future.

\section{Rice combines two strategies for iron acquisition}

Rice (Oryza sativa) secretes 2'-Deoxymugineic acid (DMA) to chelate $\mathrm{Fe}^{3+}$ from the soil and increase its solubility. DMA is synthesized from S-adenosylmethionine through three successive enzymatic reactions catalyzed by nicotianamine synthase (NAS), ${ }^{58}$ nicotianamine aminotransferase (NAAT) ${ }^{59}$ and deoxymugineic acid synthase (DMAS) ${ }^{60}$ The expression of NAS, NAAT and DMAS genes is largely induced under iron deficiency in roots. DMA are then secreted in the rhizosphere by Transporter Of Mugineic acid family phytosiderophores 1 (TOM1) (Fig. 1B). When expressed in Xenopus oocytes, TOM1 behaves as a DMA efflux transporter. ${ }^{17}$ In rice, TOM1 is expressed in root in response to iron deficiency and its overexpression and silencing lead to an increase and a decrease of DMA secretion, respectively. Consistently, plants overexpressing TOM1 are more tolerant to iron deficiency. ${ }^{17}$ Apart from TOM1, another efflux transporter named Phenolics Efflux Transporter 2 (PEZ2) was proposed to be involved in rice iron acquisition by exporting phenolic compounds such as protocatechuic acid and caffeic acid in the rhizosphere to increase iron solubility. ${ }^{61}$ In graminaceae, protocatechuic acid may thus play a similar role to solubilize Fe as fraxetin, esculetin and sideretin in dicots. After iron chelation, $\mathrm{Fe}^{3+}$-DMA complexes are transported into root epidermal cells by a Yellow Stripe1-Like (YSL) protein named OsYSL15 (Fig. 1B). OsYSL15 gene is mostly expressed in root epidermis/exodermis and phloem cells under iron deficiency and its knockdown leads to severe defects in germination and early seedling growth that are reverted by iron supply. ${ }^{62}$ In addition, insertional osys/15 mutants were shown to exhibit reduced iron concentrations. ${ }^{63}$ Other members of the OsYSL family may be implicated in iron uptake from the rhizosphere. Thus, OsYSL16 protein transports $\mathrm{Fe}^{3+}-\mathrm{DMA}$ as revealed by a complementation assay performed on the yeast fet3fet 4 mutant defective in iron uptake and OsYSL16 gene is expressed in the rice root epidermis, but contrary to OSYSL15, independently of the iron status of the plant. ${ }^{64}$ This suggests that rice combines a constitutive and an inducible component for Fesiderophore complex uptake. 
Although rice is considered as a strategy II plant for iron uptake, it also uses mechanisms from strategy I. Indeed, rice was demonstrated to directly absorb $\mathrm{Fe}^{2+}$ from the soil in addition to $\mathrm{Fe}^{3+}-$ phytosiderophore complexes (Fig. 1B). ${ }^{65}$ This process is likely mediated by the OsIRT1 and OsIRT2 transporters since: (i) similarly to other iron acquisition components, OsIRT1 and OsIRT2 are expressed in roots under iron deficiency, (ii) both proteins are localized in the plasma membrane, (iii) OsIRT1 and OsIRT2 transport Fe ${ }^{2+}$ as revealed by yeast complementation assays. ${ }^{65,66}$ This second system allowing $\mathrm{Fe}^{2+}$ acquisition would be in accordance with the fact that rice secretes relatively low amount of phytosiderophores compared to other graminaceous plants. ${ }^{67}$ Contrary to the Arabidopsis iron acquisition strategy, the activity of FRO ferric reductase seems to be dispensable for $\mathrm{Fe}^{2+}$ uptake under iron deficiency in rice, suggesting that OsIRT1 works independently of FRO proteins. ${ }^{65}$ In paddy fields, where rice is grown, $\mathrm{Fe}^{2+}$ is abundant due to the low redox potential and therefore rice plants do not need to reduce $\mathrm{Fe}^{3+}$ to $\mathrm{Fe}^{2+}$. However, Ishimaru and co-workers showed that enhancing the root $\mathrm{Fe}^{3+}$ chelate-reductase activity of rice plants by expressing the mutational reconstructed yeast $\mathrm{Fe}^{3+}$ chelatereductase gene refre1/372, under the control of OSIRT1 promoter, conferred resistance to low iron availability on calcareous soils. ${ }^{68}$ The combined strategy for iron acquisition is not specific to 0 . sativa but is also present in wild species of the Oryza genus, demonstrating that the adaptation to $\mathrm{Fe}^{2+}$ uptake in flooded soils precedes 0 . sativa domestication. ${ }^{69}$ Some authors recently proposed that, apart from rice, other graminaceous plants such as maize may combined strategy II and some features of archetypal strategy I system for iron acquisition. ${ }^{70}$

\section{An overview of Fe uptake strategies in different organisms related to plants}

The origin of the diversity of Fe uptake systems found in land plants may be traced back in unicellular algae. Iron is also a major limiting factor for the growth of phytoplankton. ${ }^{71}$ Iron solubility depends on $\mathrm{pH}$, carbonate concentration and temperature. ${ }^{72} \mathrm{Fe}$ is scarcely available in well oxygenated water and most of the iron is bound to organic compounds or colloid particles of oxyhydroxides, as in soils. To cope with the extreme scarcity of this element and adapt to the diversity of Fe sources and their changes according to environmental factors, unicellular algae have evolved a plethora of iron acquisition systems that often coexist in the same species. This is well illustrated by the study of Fe uptake systems in the two main algal models: Chlamydomonas reinhardtii and the diatom Phaeodactylum tricornutum. They both possess reductive and non-reductive strategies for iron acquisition (Fig. 1C). Interestingly, when reduction-based iron uptake coexists with another iron acquisition system, the expression of the genes involved in the different iron acquisition strategies are co-regulated, as demonstrated in C. reinhardtii but also in rice by analyses of transcriptomic data. ${ }^{73}$ For 
non-reductive uptake, $P$. tricornutum and $C$. reinhardtii use a transferrin-like (phyto-transferrin) protein, named Iron Starvation Induced protein 2A (ISIP2A) and Fe-assimilating protein 1 and 2 (FEA1 /FEA2), respectively, that bind $\mathrm{Fe}^{3+}$ in the extracellular space. ISIP2A has a transmembrane domain and was shown to be internalized by endocytosis. ${ }^{74}$ In contrast, FEA1 and FEA2 are secreted and the mechanism for their recovery has not been identified yet. ${ }^{75}$ There are evidences for similar involvement of phyto-transferrin in many other algae, such as the halotolerant species Dunaliella salina ${ }^{76}$, Chromera velia ${ }^{77}$ and Ostreococcus tauri. ${ }^{78}$ Interestingly, no phyto-transferrin-based Fe uptake pathway has been identified in land plants. ${ }^{79}$ This system may have been lost upon land colonization or was not present in the specific algal lineage that gave rise to land plants. Intriguingly, the expression of FEA1 protein from C. reinhardtii is able to complement the Arabidopsis iron-transporter mutant irt1, suggesting that a pathway allowing the internalization of phyto-transferrins bound to iron is likely conserved in Arabidopsis. ${ }^{79}$ Although algae do not produce siderophores, $P$. tricornutum is able to take up $\mathrm{Fe}^{3+}$ chelated by siderophores of bacterial origin. Siderophore- $\mathrm{Fe}^{3+}$ uptake involves the ISIP1 protein and its endocytosis (Fig. 1C). ${ }^{80}$ ISIP1 is diatom specific and it is unknown whether any other algae are able to take up iron via a similar mechanism. So far, there is only one report of a putative uptake of the bacterial siderophore pyoverdin by land plants. ${ }^{81}$ Algae are also able to use a reductive pathway for Fe acquisition (Fig. 1C). It involves the Ferric Reductase FRE, an homologue of FRO2 in land plants and FRE1 in yeast. ${ }^{82,83}$ However, some algal species, such as Ostreococcus tauri, have very low ferric reductase activity. ${ }^{84}$ After reduction, ferrous iron should be rapidly taken up by the cell through the action of metal transporters. So far, the molecular identity of such transporters is not clearly established. In C. reinhardtii, the transcription of two Zinc and Iron regulated transport-like Proteins (ZIP) family genes is up-regulated upon Fe deficiency. ${ }^{75}$ Thus, ZIP may constitute good candidates for $\mathrm{Fe}^{2+}$ uptake in this species. In $P$. tricornutum, ZIP and NRAMP homologues have also been identified but their subcellular localization and transport abilities remain to be determined. ${ }^{85}$ Once the $\mathrm{Fe}^{2+}$ transporters will be identified in algae, it would be interesting to determine if they function as a complex with the ferric chelate reductase as in Arabidopsis. In yeast, high affinity Fe uptake requires the copper-dependent ferrous iron oxidase FET3 that oxidized ferrous iron prior to its uptake as ferric iron by the FTR1 transporter ${ }^{86}$ Interestingly, FET3 and FTR1 proteins form a complex, which couples oxidation to uptake and prevents precipitation of ferric iron after the oxidation step. ${ }^{87}$ Similarly to yeast, a complex including the ferroxidase FOX1 and the $\mathrm{Fe}^{3+}$ permease FTR1 has been identified in C. reinhardtii. ${ }^{88}$ As for yeast FET3, copper is a cofactor of FOX1 in C. reinhardtii, linking Cu homeostasis and Fe uptake. ${ }^{89}$ However, contrary to yeast, copper deficiency does not result in secondary Fe deficiency in $C$. reinhardtii. This may be due to the presence of an alternative system to take up ferric Fe via FEA1/2 proteins, that are not present in yeast. ${ }^{89}$ Homologue genes encoding FOX1 and FTR1 proteins are present in diatom genomes but their role in 
Fe uptake has not been investigated yet. ${ }^{85}$ In contrast, land plants do not seem to possess a homologous Fe uptake pathway coupling Fe oxidation to high affinity uptake of ferric iron.

Except the involvement of a ferric reductase, the majority of the systems used in algae for iron uptake are not present in land plants. These systems were probably rapidly lost upon land colonization, since iron acquisition in the basal terrestrial photosynthetic organism Marchantia polymorpha seems to mainly rely on a reductive pathway very similar to the one active in dicots..$^{90}$ Conversely, most of the molecular components of strategy I and II are not present in algae, which raises intriguing questions on their evolutionary origin.

\section{Conclusions and future work directions}

- Fe reduction strategy seems to be the ancestral Fe uptake mechanism of land plants and unicellular algae, sharing features with the reduction strategy of other organisms such as Marchantia polymorpha.

- The necessity of forming a complex to optimize the process of Fe uptake when it depends on the coordinated action of different proteins seems of great importance in different organisms.

- The iron uptake mechanisms in Arabidopsis are well described and the intracellular dynamics of the proteins that form the iron-acquisition complex are starting to be uncovered, especially for the IRT1 iron transporter. Still, the biological importance of the formation of such a complex will have to be thoroughly characterized in the future.

- In Arabidopsis, several ferric reductases have been identified ${ }^{91}$. They may be involved in Fe reduction and subsequent acquisition in different plant tissues and organelles. Whether different iron-reducing platforms exist in plants remains on open question. In the future, knowledge gained about root iron uptake may be applied to study Fe mobilization in sink tissues, including the loading of iron in flowers and seeds.

\section{Acknowledgments}

This work was funded by the French National Research Agency (ANR-18-CE20-0008, NUTRIR project, to E.Z., ANR-13-JSV2-0004-01, to G.V. and ANR-17-CE20-0008, to S.T.), by the French Laboratory of Excellence project "TULIP" (ANR-10-LABX-41 and ANR-11-IDEX-0002-02 to G.V.) and by Marie Curie Actions (PCIG-GA-2012-334021, to G.V.). We thank Xia Gao for the proofreading of the section concerning the iron uptake in unicellular algae. 
326 1. Rochaix JD. Reprint of: Regulation of photosynthetic electron transport. Biochim Biophys Acta -

327 Bioenerg 2011;1807:878-86. doi: 10.1016/j.bbabio.2011.05.009

328 2. Kroh GE, Pilon M. Regulation of iron homeostasis and use in chloroplasts. Int J Mol Sci 2020;21.

329 doi: $10.3390 /$ ijms21093395

330 3. Hubmacher D, Matzanke BF, Anemüller S. Effects of iron limitation on the respiratory chain and

331 the membrane cytochrome pattern of the euryarchaeon Halobacterium salinarum. Biol Chem

332 2003;384:1565-73. doi: 10.1515/BC.2003.173

333 4. Miller A-F. Superoxide dismutases: ancient enzymes and new insights. FEBS Lett 2012;586:58595. doi: 10.1016/j.febslet.2011.10.048

5. Puig S, Ramos-Alonso L, Romero AM, Martínez-Pastor MT. The elemental role of iron in DNA synthesis and repair. Metallomics 2017;9:1483-500. doi: 10.1039/c7mt00116a

6. Briat J, Lobrag S. Iron transport and storage in plants. Trends Plant Sci 1997;2:187-93. doi: 10.1016/S1360-1385(97)85225-9

7. Thomine S, Vert G. Iron transport in plants: Better be safe than sorry. Curr Opin Plant Biol 2013;16:322-7. doi: 10.1016/j.pbi.2013.01.003

8. Schwertmann U. Solubility and dissolution of iron oxides. Plant Soil 1991;130:1-25. doi: 10.1007/BF00011851

9. Rengel Z. Availability of Mn, Zn and Fe in the rhizosphere. J Soil Sci Plant Nutr 2015;15:397-409. doi: 10.4067/s0718-95162015005000036

10. Marschner H, Romheld V, Kissel M. Different strategies in higher plants in mobilization and uptake of iron. J Plant Nutr 1986;9:695-713. doi: 10.1080/01904168609363475

347 11. Marschner H, Römheld V. Strategies of plants for acquisition of iron. Plant Soil 1994;165:261-74.

348 12. Ohwaki Y, Sugahara K. Active extrusion of protons and exudation of carboxylic acids in response to 349 iron deficiency by roots of chickpea (Cicer arietinum L.). Plant Soil 1997;189:49-55. doi: 10.1023/A:1004271108351

13. Romera FJ, Alcántara E, De la Guardia MD. Influence of bicarbonate and metal ions on the development of root Fe(III) reducing capacity by Fe-deficient cucumber (Cucumis sativus) plants. Physiol Plant 1997;101:143-8. doi: 10.1034/j.1399-3054.1997.1010119.x

14. Alcántara E, Romera FJ, Cañete M, De la Guardia MD. Effects of bicarbonate and iron supply on

15. Lucena C, Romera FJ, Rojas CL, García MJ, Alcántara E, Pérez-Vicente R. Bicarbonate blocks the expression of several genes involved in the physiological responses to Fe deficiency of Strategy I plants. Funct Plant Biol 2007;34:1002-9. doi: 10.1071/FP07136

16. Takagi S, Nomoto K, Takemoto T. Physiological aspect of mugineic acid, a possible phytosiderophore of graminaceous plants. J Plant Nutr 1984;7:469-77. doi: 10.1080/01904168409363213

363 17. Nozoye T, Nagasaka S, Kobayashi T, Takahashi M, Sato Y, Sato Y, Uozumi N, Nakanishi H, Nishizawa 
NK. Phytosiderophore efflux transporters are crucial for iron acquisition in graminaceous plants. J Biol Chem 2011;286:5446-54. doi: 10.1074/jbc.M110.180026

18. Curie C, Panaviene Z, Loulergue C, Dellaporta SL, Briat JF, Walker EL. Maize yellow stripe1 encodes a membrane protein directly involved in Fe(III) uptake. Nature 2001;409:346-9. doi: $10.1038 / 35053080$

19. Harper JF, Manney L, DeWitt ND, Yoo MH, Sussman MR. The Arabidopsis thaliana plasma membrane H+-ATPase multigene family. Genomic sequence and expression of a third isoform. J Biol Chem 1990;265:13601-8. doi: 10.1016/s0021-9258(18)77391-2

20. Fuglsang AT, Guo Y, Cuin TA, Qiu Q, Song C, Kristiansen KA, Bych K, Schulz A, Shabala S, Schumaker KS, et al. Arabidopsis Protein Kinase PKS5 Inhibits the Plasma Membrane H+-ATPase by Preventing Interaction with 14-3-3 Protein. Plant Cell 2007;19:1617-34. doi: 10.1105/tpc.105.035626

21. Santi S, Schmidt W. Dissecting iron deficiency-induced proton extrusion in Arabidopsis roots. New Phytol 2009;183:1072-84. doi: 10.1111/j.1469-8137.2009.02908.x

22. Yi Y, Guerinot M Lou. Genetic evidence that induction of root Fe(III) chelate reductase activity is necessary for iron uptake under iron deficiency. Plant J.1996;10:835-44. doi: 10.1046/j.1365313X.1996.10050835.X

23. Connolly E., Campbell N., Grotz N, Prichard C., Guerinot M. Overexpression of the FRO2 Ferric Chelate Reductase Confers Tolerance to Growth on Low Iron and Uncovers Posttranscriptional Control 1. Plant Physiol 2003;133:1102-10. doi: 10.1104/pp.103.025122

24. Mukherjee I, Campbell NH, Ash JS, Connolly EL. Expression profiling of the Arabidopsis ferric chelate reductase (FRO) gene family reveals differential regulation by iron and copper. Planta 2006;223:1178-90. doi: 10.1007/s00425-005-0165-0

25. Schagerlöf U, Wilson G, Hebert H, Al-Karadaghi S, Hägerhäll C. Transmembrane topology of FRO2, a ferric chelate reductase from Arabidopsis thaliana. Plant Mol Biol 2006;62:215-21. doi: 10.1007/s11103-006-9015-0

26. Eide D, Broderius M, Fett J, Guerinot ML. A novel iron-regulated metal transporter from plants identified by functional expression in yeast. Proc Natl Acad Sci U S A 1996;93:5624-8.

27. Korshunova YO, Eide D, Clark WG, Guerinot M Lou, Pakrasi HB. The IRT1 protein from Arabidopsis thaliana is a metal transporter with a broad substrate range. Plant Mol Biol 1999;40:37-44. doi: 10.1023/A: 1026438615520

28. Rogers EE, Eide DJ, Guerinot ML. Altered selectivity in an Arabidopsis metal transporter. Proc Natl Acad Sci 2000;97:12356-60. doi: 10.1073/pnas.210214197

29. Vert G, Briat JF, Curie C. Arabidopsis IRT2 gene encodes a root-periphery iron transporter. Plant J 2001;26:181-9. doi: 10.1046/j.1365-313X.2001.01018.x

30. Vert G, Grotz N, Dédaldéchamp F, Gaymard F, Guerinot M Lou, Briat J-F, Curie C. IRT1, an Arabidopsis Transporter Essential for Iron Uptake from the Soil and for Plant Growth. Plant Cell 2002;14:1223 LP - 1233. doi: 10.1105/tpc.001388

31. Colangelo EP, Guerinot M Lou. The Essential Basic Helix-Loop-Helix Protein FIT1 Is Required for the Iron Deficiency Response. Plant Cell 2004;16:3400 LP - 3412. doi: 10.1105/tpc.104.024315 
32. Jakoby M, Wang HY, Reidt W, Weisshaar B, Bauer P. FRU (BHLH029) is required for induction of iron mobilization genes in Arabidopsis thaliana. FEBS Lett 2004;577:528-34. doi: 10.1016/j.febslet.2004.10.062

33. Yuan Y, Wu H, Wang N, Li J, Zhao W, Du J, Wang D, Ling HQ. FIT interacts with AtbHLH38 and AtbHLH39 in regulating iron uptake gene expression for iron homeostasis in Arabidopsis. Cell Res 2008;18:385-97. doi: 10.1038/cr.2008.26

34. Abadía J, López-Millán AF, Rombolà A, Abadía A. Organic acids and Fe deficiency: A review. Plant Soil 2002;241:75-86. doi: 10.1023/A:1016093317898

35. Chong WJ, Guang YY, Yun FH, Tang C, Wu P, Shao JZ. Iron Deficiency-Induced Secretion of Phenolics Facilitates the Reutilization of Root Apoplastic Iron in Red Clover. Plant Physiol 2007;144:278-85. doi: 10.1104/pp.107.095794

36. Clemens S, Weber M. The essential role of coumarin secretion for Fe acquisition from alkaline soil. Plant Signal Behav 2016;11:1-6. doi: 10.1080/15592324.2015.1114197

37. Connorton JM, Balk J, Rodríguez-Celma J. Iron homeostasis in plants - a brief overview. Metallomics 2017;9:813-23. doi: 10.1039/c7mt00136c

38. Schmid NB, Giehl RFH, Doll S, Mock H-P, Strehmel N, Scheel D, Kong X, Hider RC, von Wiren N. Feruloyl-CoA 6'-Hydroxylase1-Dependent Coumarins Mediate Iron Acquisition from Alkaline Substrates in Arabidopsis. Plant Physiol 2014;164:160-72. doi: 10.1104/pp.113.228544

39. Rajniak J, Giehl RFH, Chang E, Murgia I, von Wirén N, Sattely ES. Biosynthesis of redox-active metabolites in response to iron deficiency in plants. Nat Chem Biol 2018;14:442-50. doi: 10.1038/s41589-018-0019-2

40. Robe K, Conejero G, Gao F, Lefebvre-Legendre L, Sylvestre-Gonon E, Rofidal V, Hem S, Rouhier N, Barberon M, Hecker A, et al. Coumarin accumulation and trafficking in Arabidopsis thaliana: a complex and dynamic process. 2021. doi: 10.1111/nph.17090

41. Fourcroy P, Sisó-Terraza P, Sudre D, Savirón M, Reyt G, Gaymard F, Abadía A, Abadia J, ÁlvarezFernández A, Briat JF. Involvement of the ABCG37 transporter in secretion of scopoletin and derivatives by Arabidopsis roots in response to iron deficiency. New Phytol 2014;201:155-67. doi: $10.1111 /$ nph.12471

42. Harbort CJ, Hashimoto M, Inoue H, Niu Y, Guan R, Rombolà AD, Kopriva S, Voges MJEEE, Sattely ES, Garrido-Oter R, et al. Root-Secreted Coumarins and the Microbiota Interact to Improve Iron Nutrition in Arabidopsis. Cell Host Microbe 2020;28:825-837.e6. doi: 10.1016/j.chom.2020.09.006

43. Curie C, Alonso JM, Le Jean M, Ecker JR, Briat JF. Involvement of NRAMP1 from Arabidopsis thaliana in iron transport. Biochem J 2000;347 Pt 3:749-55.

44. Castaings L, Caquot A, Loubet S, Curie C. The high-affinity metal Transporters NRAMP1 and IRT1 Team up to Take up Iron under Sufficient Metal Provision. Sci Rep 2016;6:1-11. doi: $10.1038 /$ srep37222

45. Dubeaux G, Neveu J, Zelazny E, Vert G. Metal Sensing by the IRT1 Transporter-Receptor Orchestrates Its Own Degradation and Plant Metal Nutrition. Mol Cell 2018;69:953-964.e5. doi: 10.1016/j.molcel.2018.02.009

46. Khan I, Gratz R, Denezhkin P, Schott-Verdugo SN, Angrand K, Genders L, Basgaran RM, Fink- 
Straube C, Brumbarova T, Gohlke H, et al. Calcium-promoted interaction between the C2-domain protein EHB1 and metal transporter IRT1 inhibits arabidopsis iron acquisition. Plant Physiol 2019;180:1564-81. doi: 10.1104/pp.19.00163

47. Martín-Barranco A, Spielmann J, Dubeaux G, Vert G, Zelazny E. Dynamic Control of the High-Affinity Iron Uptake Complex in Root Epidermal Cells. Plant Physiol 2020;184:1236-50. doi: $10.1104 /$ pp.20.00234

48. Barberon M, Dubeaux G, Kolb C, Isono E, Zelazny E, Vert G. Polarization of IRON-REGULATED TRANSPORTER 1 (IRT1) to the plant-soil interface plays crucial role in metal homeostasis. Proc Natl Acad Sci 2014;111:8293-8. doi: 10.1073/pnas.1402262111

49. Barberon M, Zelazny E, Robert S, Conéjéro G, Curie C, Friml J, Vert G. Monoubiquitin-dependent endocytosis of the transporter controls iron uptake in plants. Proc Natl Acad Sci U S A 2011;108:e450-8. doi: 10.1073/pnas.1100659108//DCSupplemental.www.pnas.org/cgi/doi/10.1073/pnas.1100659108

50. Łangowski Ł, Růžička K, Naramoto S, Kleine-Vehn J, Friml J. Trafficking to the Outer Polar Domain Defines the Root-Soil Interface. Curr Biol 2010;20:904-8. doi: 10.1016/j.cub.2010.03.059

51. Lipka V, Dittgen J, Bednarek P, Bhat R, Wiermer M, Stein M, Landtag J, Brandt W, Rosahl S, Scheel D, et al. Plant science: Pre- and postinvasion defenses both contribute to nonhost resistance in Arabidopsis. Science (80- ) 2005;310:1180-3. doi: 10.1126/science.1119409

52. Stein M, Dittgen J, Sánchez-Rodríguez C, Hou B-H, Molina A, Schulze-Lefert P, Lipka V, Somerville S. Arabidopsis PEN3/PDR8, an ATP binding cassette transporter, contributes to nonhost resistance to inappropriate pathogens that enter by direct penetration. Plant Cell 2006;18:731-46. doi: 10.1105/tpc.105.038372

53. Kim D-Y, Bovet L, Maeshima M, Martinoia E, Lee Y. The ABC transporter AtPDR8 is a cadmium extrusion pump conferring heavy metal resistance. Plant J 2007;50:207-18. doi: 10.1111/j.1365313X.2007.03044.X

54. Bednarek P, Piślewska-Bednarek M, Svatoš A, Schneider B, Doubský J, Mansurova M, Humphry M, Consonni C, Panstruga R, Sanchez-Vallet A, et al. A Glucosinolate Metabolism Pathway in Living Plant Cells Mediates Broad-Spectrum Antifungal Defense. Science (80-) 2009;323:101 LP - 106. doi: 10.1126/science.1163732

55. Strader LC, Bartel B. The arabidopsis PLEIOTROPIC DRUG RESISTANCE8/ABCG36 ATP binding cassette transporter modulates sensitivity to the auxin precursor lndole-3-butyric acid. Plant Cell 2009;21:1992-2007. doi: 10.1105/tpc.109.065821

56. Badri D V., Loyola-Vargas VM, Broeckling CD, De-la-Peña C, Jasinski M, Santelia D, Martinoia E, Sumner LW, Banta LM, Stermitz F, et al. Altered profile of secondary metabolites in the root exudates of arabidopsis ATP-binding cassette transporter mutants. Plant Physiol 2008;146:76271. doi: 10.1104/pp.107.109587

57. Ziegler J, Schmidt S, Strehmel N, Scheel D, Abel S. Arabidopsis Transporter ABCG37/PDR9 contributes primarily highly oxygenated Coumarins to Root Exudation. Sci Rep 2017;7:1-11. doi: 10.1038/s41598-017-03250-6

58. Higuchi K, Watanabe S, Takahashi M, Kawasaki S, Nakanishi H, Nishizawa NK, Mori S. 
Nicotianamine synthase gene expression differs in barley and rice under Fe-deficient conditions. Plant J 2001;25:159-67. doi: 10.1046/j.1365-313X.2001.00951.x

59. Inoue H, Takahashi M, Kobayashi T, Suzuki M, Nakanishi H, Mori S, Nishizawa NK. Identification and localisation of the rice nicotianamine aminotransferase gene OsNAAT1 expression suggests the site of phytosiderophore synthesis in rice. Plant Mol Biol 2008;66:193-203. doi: 10.1007/s11103-007-9262-8

60. Bashir K, Inoue H, Nagasaka S, Takahashi M, Nakanishi H, Mori S, Nishizawa NK. Cloning and characterization of deoxymugineic acid synthase genes from graminaceous plants. J Biol Chem 2006;281:32395-402. doi: 10.1074/jbc.M604133200

61. Bashir K, Ishimaru Y, Shimo H, Kakei Y, Senoura T, Takahashi R, Sato Y, Sato Y, Uozumi N, Nakanishi H, et al. Rice phenolics efflux transporter 2 (PEZ2) plays an important role in solubilizing apoplasmic iron. Soil Sci Plant Nutr 2011;57:803-12. doi: 10.1080/00380768.2011.637305

62. Inoue H, Kobayashi T, Nozoye T, Takahashi M, Kakei Y, Suzuki K, Nakazono M, Nakanishi H, Mori S, Nishizawa NK. Rice OsYSL15 is an iron-regulated iron (III)-deoxymugineic acid transporter expressed in the roots and is essential for iron uptake in early growth of the seedlings. J Biol Chem 2009;284:3470-9. doi: 10.1074/jbc.M806042200

63. Lee S, Chiecko JC, Kim SA, Walker EL, Lee Y, Guerinot M Lou, An G. Disruption of OsYSL15 leads to iron inefficiency in rice plants. Plant Physiol 2009;150:786-800. doi: 10.1104/pp.109.135418

64. Kakei Y, Ishimaru Y, Kobayashi T, Yamakawa T, Nakanishi H, Nishizawa NK. OsYSL16 plays a role in the allocation of iron. Plant Mol Biol 2012;79:583-94. doi: 10.1007/s11103-012-9930-1

65. Ishimaru Y, Suzuki M, Tsukamoto T, Suzuki K, Nakazono M, Kobayashi T, Wada Y, Watanabe S, Matsuhashi S, Takahashi M, et al. Rice plants take up iron as an Fe3+-phytosiderophore and as Fe2+. Plant J 2006;45:335-46. doi: 10.1111/j.1365-313X.2005.02624.x

66. Bughio N, Yamaguchi H, Nishizawa NK, Nakanishi H, Mori S. Cloning an iron-regulated metal transporter from rice. J Exp Bot 2002;53:1677-82. doi: 10.1093/jxb/erf004

67. Mori S, Nishizawa N, Hayashi H, Chino M, Yoshimura E, Ishihara J. Why are young rice plants highly susceptible to iron deficiency? Plant Soil 1991;130:143-56. doi: 10.1007/BF00011869

68. Ishimaru Y, Kim S, Tsukamoto T, Oki H, Kobayashi T, Watanabe S, Matsuhashi S, Takahashi M, Nakanishi H, Mori S, et al. Mutational reconstructed ferric chelate reductase confers enhanced tolerance in rice to iron deficiency in calcareous soil. Proc Natl Acad Sci 2007;104:7373 LP - 7378. doi: 10.1073/pnas.0610555104

69. Wairich A, de Oliveira BHN, Arend EB, Duarte GL, Ponte LR, Sperotto RA, Ricachenevsky FK, Fett JP. The Combined Strategy for iron uptake is not exclusive to domesticated rice (Oryza sativa). Sci Rep 2019;9:1-17. doi: 10.1038/s41598-019-52502-0

70. Long L, Persson DP, Duan F, Jørgensen K, Yuan L, Schjoerring JK, Pedas PR. The iron-regulated transporter 1 plays an essential role in uptake, translocation and grain-loading of manganese, but not iron, in barley. New Phytol 2018;217:1640-53. doi: 10.1111/nph.14930

71. Morel FMM, Hudson RJM, Price NM. Limitation of productivity by trace metals in the sea. Limnol Oceanogr 1991;36:1742-55. doi: 10.4319/lo.1991.36.8.1742 
72. Hoffmann LJ, Breitbarth E, Boyd PW, Hunter KA. Influence of ocean warming and acidification on trace metal biogeochemistry. Mar Ecol Prog Ser 2012;470:191-205. doi: 10.3354/meps10082

73. Ivanov R, Bauer P. Sequence and coexpression analysis of iron-regulated ZIP transporter genes reveals crossing points between iron acquisition strategies in green algae and land plants. Plant Soil 2017;418:61-73. doi: 10.1007/s11104-016-3128-2

74. McQuaid JB, Kustka AB, Oborník M, Horák A, McCrow JP, Karas BJ, Zheng H, Kindeberg T, Andersson AJ, Barbeau KA, et al. Carbonate-sensitive phytotransferrin controls high-affinity iron uptake in diatoms. Nature 2018;555:534-7. doi: 10.1038/nature25982

75. Allen MD, Del Campo JA, Kropat J, Merchant SS. FEA1, FEA2, and FRE1, encoding two homologous secreted proteins and a candidate ferrireductase, are expressed coordinately with FOX1 and FTR1 in iron-deficient Chlamydomonas reinhardtii. Eukaryot Cell 2007;6:1841-52. doi: 10.1128/EC.00205-07

76. Fisher M, Zamir A, Pick U. Iron uptake by the halotolerant alga Dunaliella is mediated by a plasma membrane transferrin. J Biol Chem 1998;273:17553-8. doi: 10.1074/jbc.273.28.17553

77. Sutak R, Šlapeta J, Roman MS, Camadro JM, Lesuisse E. Nonreductive iron uptake mechanism in the marine alveolate Chromera velia. Plant Physiol 2010;154:991-1000. doi: 10.1104/pp.110.159947

78. Lelandais G, Scheiber I, Paz-Yepes J, Lozano JC, Botebol H, Pilátová J, Žárský V, Léger T, Blaiseau PL, Bowler C, et al. Ostreococcus tauri is a new model green alga for studying iron metabolism in eukaryotic phytoplankton. BMC Genomics 2016;17:1-23. doi: 10.1186/s12864-016-2666-6

79. Narayanan NN, Ihemere U, Chiu W, Siritunga D, Rajamani S, Singh S, Oda S, Sayre RT. The iron assimilatory protein, FEA1, from Chlamydomonas reinhardtii facilitates iron-specific metal uptake in yeast and plants. Front Plant Sci 2011;2:1-13. doi: 10.3389/fpls.2011.00067

80. Kazamia E, Sutak R, Paz-Yepes J, Dorrell RG, Vieira FRJ, Mach J, Morrissey J, Leon S, Lam F, Pelletier E, et al. Endocytosis-mediated siderophore uptake as a strategy for Fe acquisition in diatoms. Sci Adv 2018;4. doi: 10.1126/sciadv.aar4536

81. Vansuyt G, Robin A, Briat JF, Curie C, Lemanceau P. Iron acquisition from Fe-pyoverdine by Arabidopsis thaliana. Mol Plant-Microbe Interact 2007;20:441-7. doi: 10.1094/MPMI-20-4-0441

82. Robinson NJ, Procter CM, Connolly EL, Guerinot ML. A ferric-chelate reductase for iron uptake from soils. Nature 1999;397:694-7. doi: Doi 10.1038/17800

83. Dancis A, Klausner RD, Hinnebusch AG, Barriocanal JG. Genetic evidence that ferric reductase is required for iron uptake in Saccharomyces cerevisiae. Mol Cell Biol 1990;10:2294-301. doi: 10.1128/mcb.10.5.2294

84. Sutak R, Botebol H, Blaiseau PL, Léger T, Bouget FY, Camadro JM, Lesuisse E. A comparative study of iron uptake mechanisms in marine microalgae: Iron binding at the cell surface is a critical step. Plant Physiol 2012;160:2271-84. doi: 10.1104/pp.112.204156

85. Gao X, Bowler C, Kazamia E. Iron metabolism strategies in diatoms. J Exp Bot 2021;72:2165-80. doi: $10.1093 / j x b / e r a a 575$

86. Singh A, Severance S, Kaur N, Wiltsie W, Kosman DJ. Assembly, activation, and trafficking of the Fet3p·Ftr1p high affinity iron permease complex in Saccharomyces cerevisiae. J Biol Chem 2006;281:13355-64. doi: 10.1074/jbc.M512042200 
87. Kwok EY, Severance S, Kosman DJ. Evidence for iron channeling in the Fet3p-Ftr1p high-affinity iron uptake complex in the yeast plasma membrane. Biochemistry 2006;45:6317-27. doi: 10.1021/bi052173c

88. Terzulli A, Kosman DJ. Analysis of the high-affinity iron uptake system at the Chlamydomonas reinhardtii plasma membrane. Eukaryot Cell 2010;9:815-26. doi: 10.1128/EC.00310-09

89. La Fontaine S, Quinn JM, Nakamoto SS, Dudley Page M, Göhre V, Moseley JL, Kropat J, Merchant S. Copper-dependent iron assimilation pathway in the model photosynthetic eukaryote Chlamydomonas reinhardtii. Eukaryot Cell 2002;1:736-57. doi: 10.1128/EC.1.5.736-757.2002 analysis of iron (Fe) acquisition system in Marchantia polymorpha. New Phytol 2016;211:569-83. doi: 10.1111/nph.13922

91. Jeong J, Connolly EL. Iron uptake mechanisms in plants: Functions of the FRO family of ferric reductases. Plant Sci 2009;176:709-14. doi: https://doi.org/10.1016/j.plantsci.2009.02.011 
A)

$\mathrm{Fe}$

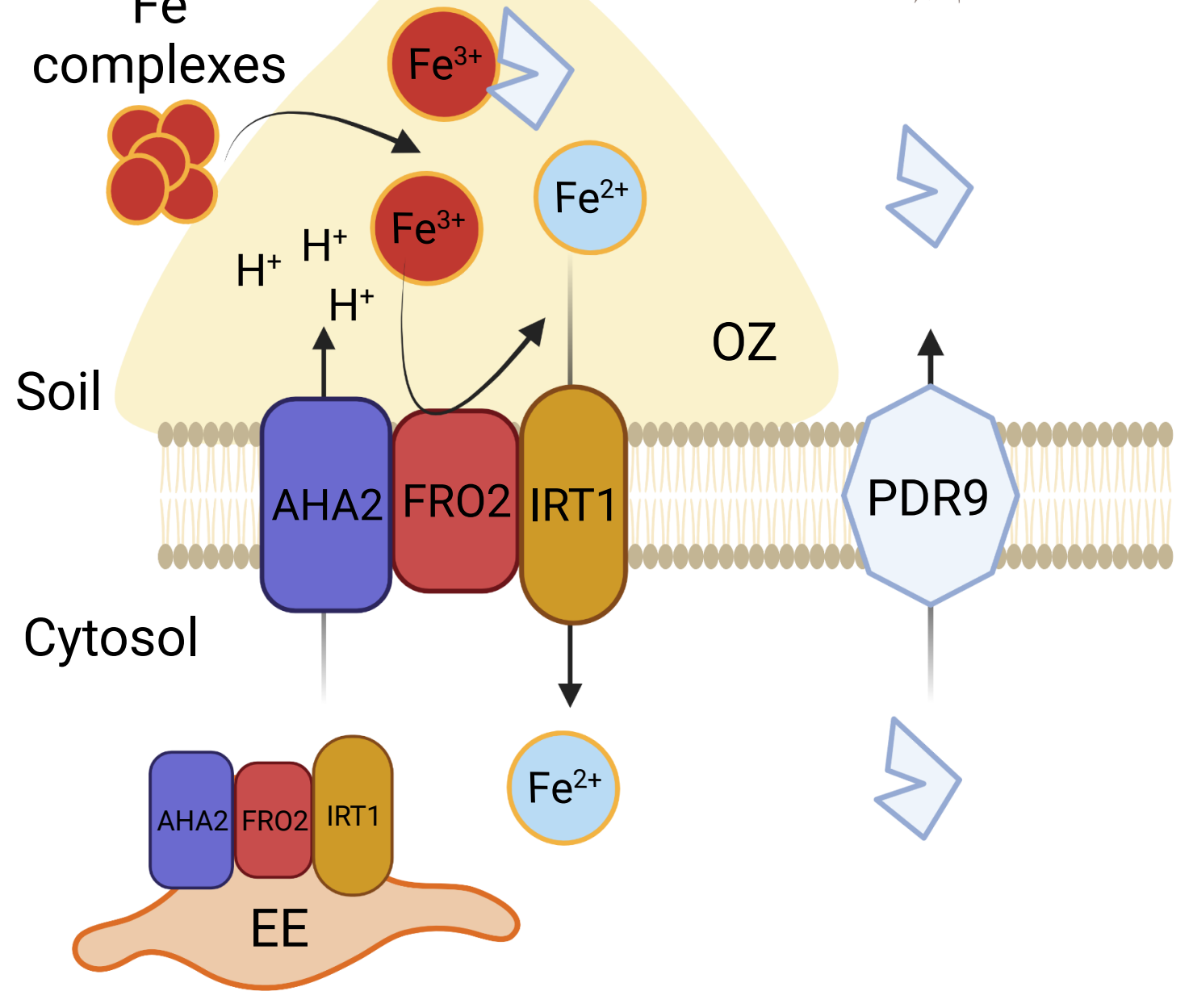

B)

$\mathrm{Fe}$

complexes

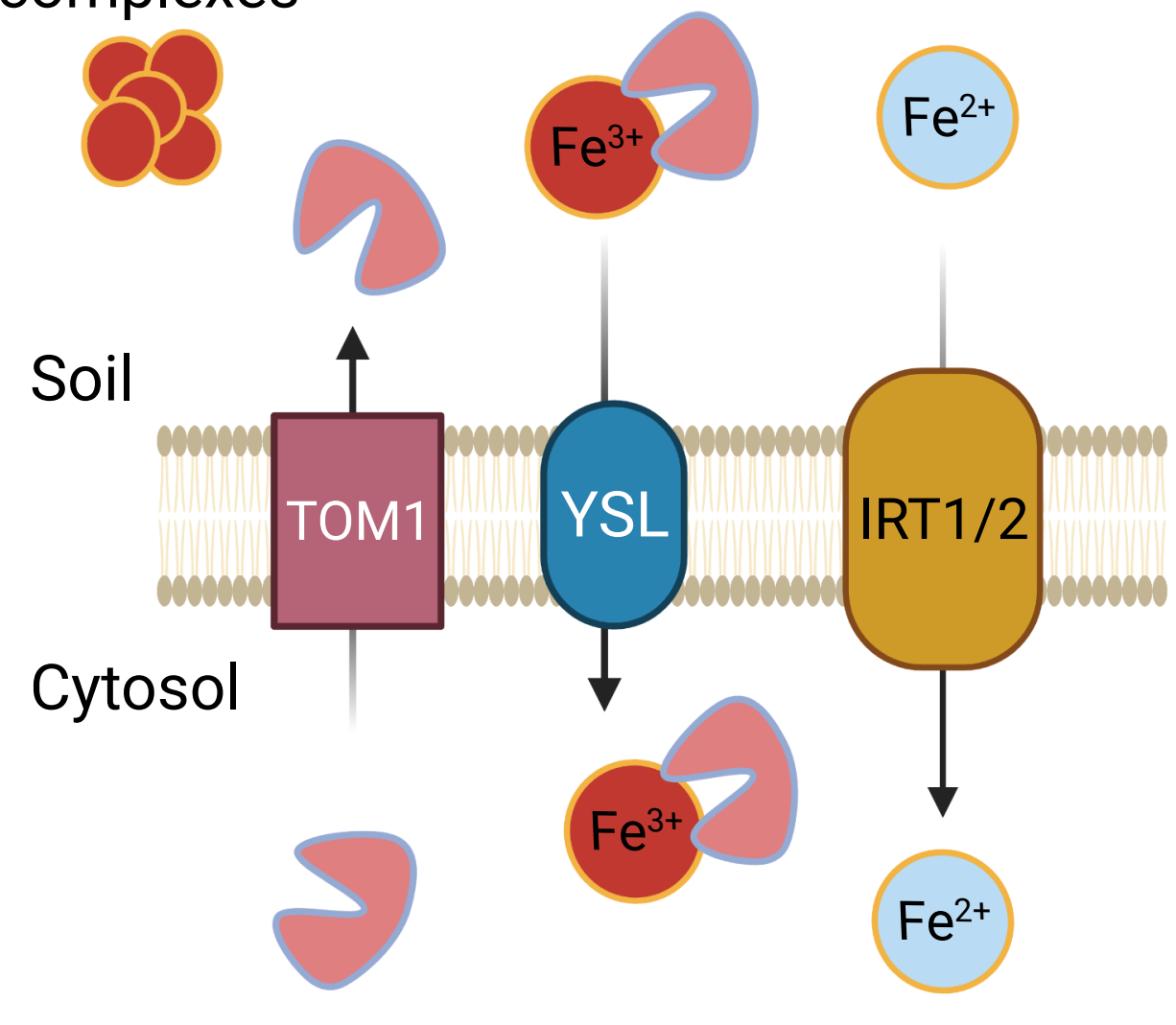

Phytosiderophore:

C)

$\mathrm{Fe}$

complexes

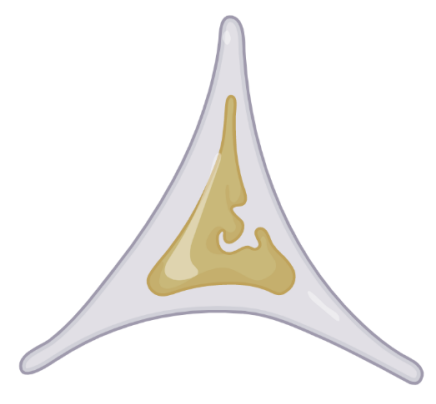

Coumarin: $\$$

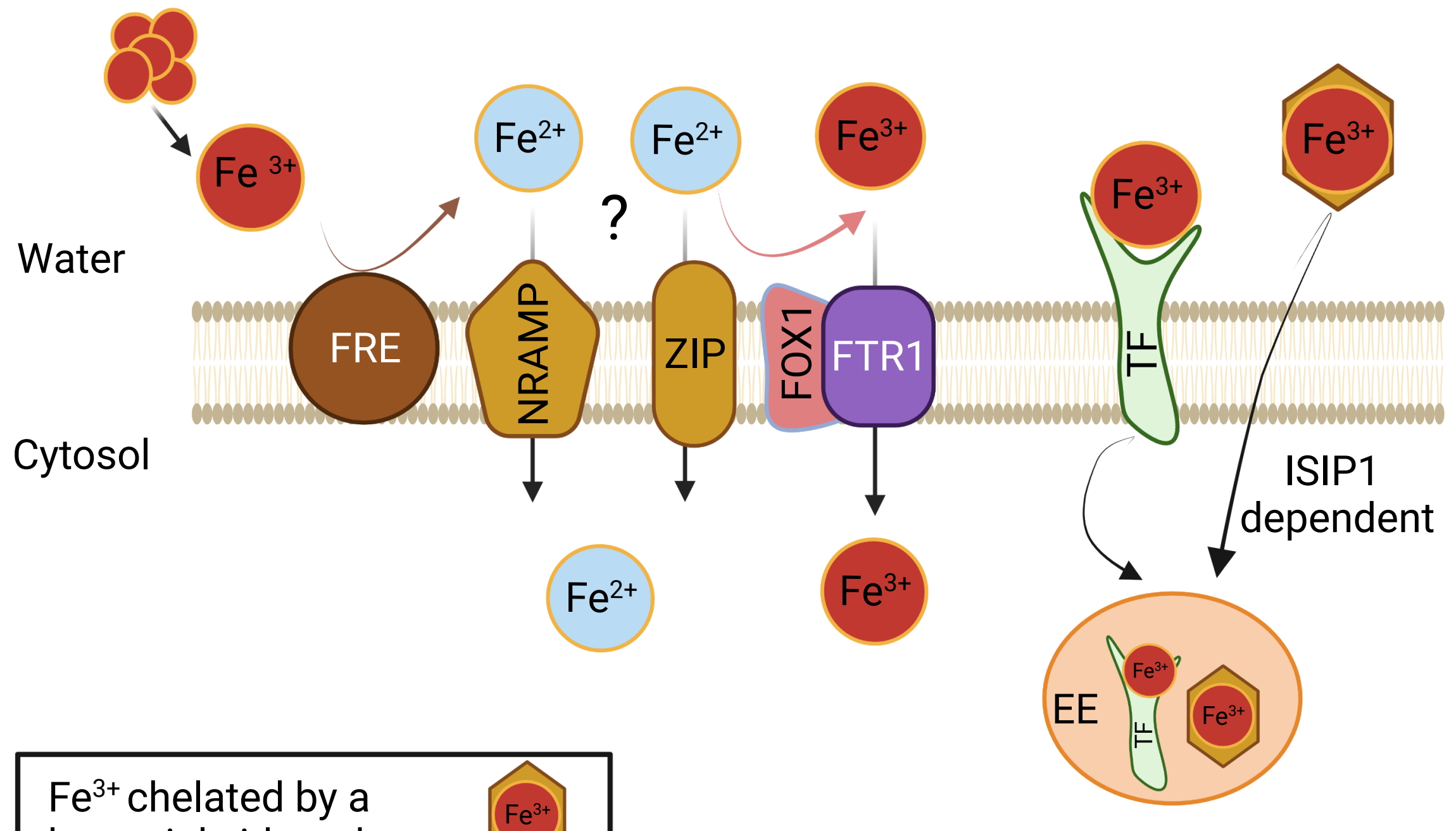

bacterial siderophore: 
Figure 1. The different iron acquisition strategies in photosynthetic organisms.

(A) Dicots and non-graminaceous monocots use an acidification-reduction-transport strategy for iron uptake, as exemplified here for Arabidopsis thaliana. The rhizosphere is acidified via proton extrusion mediated by the AHA2 proton pump, which induces the solubilization of $\mathrm{Fe}^{3+}$ complexes. Then, solubilized $\mathrm{Fe}^{3+}$ is reduced to $\mathrm{Fe}^{2+}$ by the $\mathrm{FRO} 2$ reductase and $\mathrm{Fe}^{2+}$ is finally transported by IRT1 inside root epidermal cells. AHA2, FRO2 and IRT1 co-localize at the outer plasma membrane domain facing the rhizosphere and in early endosomes (EE). These proteins are able to interact altogether to form an iron-acquisition complex that may optimize Fe absorption by creating a local environment with low $\mathrm{pH}$ and high $\mathrm{Fe}^{2+}$ concentration (optimal zone (OZ), represented in pale yellow). Coumarin release, mediated by PDR9 transporter, contributes to the Fe acquisition process. (B) Iron acquisition mechanisms in the graminaceous monocot Oryza sativa. TOM1 protein allows the secretion in the rhizosphere of phytosiderophores, mainly 2'-Deoxymugineic acid, that chelate $\mathrm{Fe}^{3+}$. Phytosiderophore$\mathrm{Fe}^{3+}$ complexes are then uptaken by YSL transporters into root epidermal cells. In addition, $\mathrm{Fe}^{2+}$ can be directly absorbed from the soil by IRT1/2 transporters. (C) Multiple iron acquisition systems co-exist in different unicellular algae such as Chlamydomonas reinhardtii and Phaeodactylum tricornutum. The reductive pathway for Fe acquisition involves the FRE ferric reductase. Produced $\mathrm{Fe}^{2+}$ may then be transported inside the cell by metal transporters from the NRAMP and ZIP families, although experimental evidences are still needed. Alternatively, $\mathrm{Fe}^{2+}$ can be re-oxidized by the FOX1 protein and then transported inside the cell by the FTR1 transporter. FTR1 forms a complex with FOX1 to prevent the precipitation of $\mathrm{Fe}^{3+}$ after the oxidation step. In some unicellular algae, transferrin-like proteins (TF) bind $\mathrm{Fe}^{3+}$ in the extracellular space and are then endocytosed, allowing Fe to enter in the cell. Furthermore, some algae can acquire Fe via the internalization of bacterial siderophores associated with $\mathrm{Fe}^{3+}$, a process involving ISIP1 protein in P. tricornutum. All the images presented in this figure were created with BioRender.com. 